\title{
Ethical and efficient research management: A new challenge for an old problem ${ }^{\star}$
}

\author{
Eva Giesen ${ }^{\star \star}$ \\ Institut National de la Santé et Recherche Médicale (Inserm), Directorate General, 101, Rue de Tolbiac, 75013 Paris, France
}

Received: 2 September 2015 / Accepted: 10 November 2015

\begin{abstract}
Scientific misconduct and questionable research practices occur on occasion because scientific research is performed by human beings. With growing pressure to produce results, competition for limited resources and in a well-informed society, however, the number of reported cases has increased more than 10 fold in 10 years. Moreover, the impact of cases of fraud, poor quality of data and unethical research management is high and scientists are concerned by this phenomenon. Codes of conduct and investigations for misconduct are in place in most fields. Preventive actions however are difficult to conduct because managerial tools are missing or unknown by scientists. Here we describe the concept of Ethical and efficient research management and its use for preventive measures against bad research practice. The concept is based on the belief that sustainable management of a research team, project or collaboration is not possible without ethical conduct of management. Ethical and efficient research and research management are thus intrinsically connected. The Inserm-Quality-Network (Riq), uses currently management tools for different purposes: organization, quality management, quality control, knowledge management, project management and so forth and has adapted them for purpose of good research practice (http://extranet.inserm.fr/ demarche-qualite/reseau-inserm-qualite).
\end{abstract}

Keywords: Scientific misconduct, questionable research practices, good management practices

\section{Introduction}

Cases of fraud have been reported and honesty in research is claimed since the early days of scientific investigations. The "Piltdown Man" case was a set of faked anthropological remains, excavated in England in 1912 and presented as those of an early human [1]. The Cyril Burt case [2] involved manipulated data on the intelligence of twins that were brought up separately (London 1954). These are only two reminders of cases that were picked up by the media and widely discussed by the scientific community and in civil society. In 2013, the Royal Netherlands Academy of Arts and Sciences asked their executive officers of the Commission on Scientific Research Data to establish an Advisory Report on "Responsible research data management and the prevention of scientific misconduct" [3] which cited Charles Babbage (1830). Already in 1830, Babbage complained about "trimming" data (elimination of too high or too low values in order to improve statistical significance and thus gain "a reputation of extreme accuracy") and of "cooking" data (which means to select from a large number of data, those which support the initial hypothesis). To him, "the forger is the one,

\footnotetext{
${ }^{\star}$ List of total number of contributing authors at the end.

${ }^{\star \star}$ Correspondence: eva.giesen@inserm.fr
}

wishing to acquire a reputation for science, records observations which he never made".

These few examples show that two (falsification and fabrication) of the three characteristics that today define Scientific Misconduct (SM) were already pointed out nearly 200 years ago. Plagiarism came later, with easy access to scientific literature, digitalization text, and the temptation to copy parts of existent publications without quoting the author. Aside from SM, bad scientific practice also includes two more items: Questionable Research Practice (QRP) and bad research management.

Modern society clearly expects sound and reproducible research and holds scientists accountable of the quality of results and the efficiency of spending of research funds.

Research results do no longer belong to solely the research community. Interesting results, but also cases of $\mathrm{SM}$, reach the public quickly via the media. For these reasons, our community has to firmly subscribe to the principles of good scientific practice, because if not, trust in science will (further) erode. In the majority of domains, research is performed by a team; therefore organization, management and valuation of teamwork is important. The latter are sustainable only when ethical and efficient research management (EERM) is provided.

Here we give an overview on existing means to DEAL with the above mentioned problems and offer, for the first 
time, a toolbox for the PREVENTION of all three aspects of research practice: SM, QRP and EERM.

\section{Bad scientific practice: the top of the iceberg or not?}

In general terms, as pointed out by the US Office of research integrity [4], "responsible conduct in research is simply good citizenship applied to professional life".

Researchers worldwide are concerned with the number of reported cases of misconduct and retracted publications by scientific journals, because of their strong impact on public trust in science, as well as good research and good research management, which include reproducible and available data and ethical behavior towards coworkers, students, the towards the scientific community and society as a whole.

There has been heavy debate over the prevalence of SM, QRP and bad research management, since published studies revealed largely varying numbers. Three types of empirical estimation studies have been conducted according to Weed [5]: analysis of accuracy of written statements, questionnaires on occurrence of SM, and audits or surveys of the data that are published by the US Office of Research Integrity. Although the phenomenon is increasing, increasingly reported and spreading towards all fields of research, the concern of the scientific community is motivated by the need to alert, rather than identifying and preventing bad or low quality of science. In the absence of converging data on prevalence, the number of cases of misconduct and retraction of scientific papers is usually thought to represent a very small fraction of research results. However other authors are less optimistic and believe that poor data and poor research management are common but hidden practice [6].

When mistakes, wrong data or scientific misconduct are detected in a publication, the article is normally retracted, e.g. the scientific journal will retrieve the publication from its database and publish a note that informs the scientific community that the article has been retracted and the reasons for retraction. The web-site www . retractionwatch.wordpress.com is a blog that tracks retracted publications and the reasons for retraction as well as various issues of misconduct.

Retraction of a flawed paper does not occur in systematic fashion, because of differing cultures and professional practices in academic fields, as well as publishing policies. Today, biomedicine is not the only discipline in which retractions occur, the fields of physics, psychology, social sciences, management and others retract articles when SM or QRP are revealed.

Most studies of the phenomenon limited their scope to articles which appear in Pubmed, thus focusing on life sciences. However, Grieneisen and Zhang surveyed 42 of the largest bibliographic databases for mayor academic fields using journals with Web of science category assignments [7]. They found that the number of retracted articles increased 19.06 fold between 2001 and 2011 or, ad- justed for growth of the published literature and multiple retractions by one author, by a factor of 11.36. Van Noordon showed that $44 \%$ of all retractions occurred because of scientific misconduct and $28 \%$ because of scientific errors [8].

There appears to be a positive correlation between a journal's citation index and the ratio of retractions. It seems as if, either high profile journals attract fraudsters or that post-publication scrutiny by the higher numbers of readers of high profile journals leads to a higher retraction index.

Flawed research has to be detected and made public by members of the team, other scientists (whistle-blowers) or during the consecutive reviewing process.

Usually fraudsters are investigated for scientific misconduct only after many years of practice. Therefore, when fraud has occurred, major repercussions on the progress of research, the trust of scientists and citizens and, in medical sciences, on patient care, are possible several years later. In todays' society, where answers are given immediate publicity and where news is rapidly spread via social networks, false information gains a wide audience. To illustrate this, we quote Katavic, who reported that within 50 days after publication of two articles showing reprogramming of somatic cells into stem cells, the news was tweeted over 3300 times. However, the articles were put under investigation for fraud 6 months later [9].

\section{Bad science and scientific misconduct: some definitions}

Scientific misconduct (SM) is usually defined as (proposed by the US Health and Human Services [9]): fabrication, falsification or plagiarism of ideas, data, or information, while performing or reviewing research or in reporting research results.

Scientific integrity (which is the opposite of SM), is something which can be clearly defined: either data have been made up or they were observed, measured and documented on site. Misconduct relates to a deliberate action, not honest error, and honest differences in interpretations or judgments, unless they are considered grossly deviant.

"Questionable research practice" (QRP) is related to bad scientific practice, to poor quality of data and research, to inappropriate methodology and so forth. To QRP belong:

- Inappropriate or poor methodology, incorrect data mining, interpretation and storage.

- "Cherry picking" (reporting only data which sustain the hypothesis or lead to a positive result), "massaging" or "cooking" data (deleting undesired data points or observations, taking only the desired data or information into account).

- "Salami-slicing" of a publication (cutting down coherent data and findings into "smallest publishable units").

- Photo manipulation for "improving" images and photo records by using computer software without giving 
precise information on the software used and what was modified on the image.

- Inadequate record keeping.

- Guest (gift, ghost) authorship. Deletion from the list of authors of a person who contributed significantly to the article.

- Not giving credit or recognition to persons who gave help, support in part of the research or technical assistance, without qualifying for the author-status.

- Failure to disclose conflicts of interest.

- Failure to share information, methods, tools, etc. with the scientific community.

"Ethical and efficient research management" (EERM) addresses points such as: respect of shared values and of coworkers and collaborators, proper training, teaching and advice of students, assuring preservation of health, safety and quality of life of a team, good project management and management of collaborative studies, compliance with rules and regulations. EERM differs from codes of conduct, because it provides a tool box for managerial practice in addition to information on good practice.

\section{Codes and standards for research and good research practice}

Different codes and standards address good scientific practice and management in general. Since 2007, a World Conference on Scientific Integrity has taken place every two to three years. The first world conference was organized by the European Science Foundation and the US Office for Research Integrity.

In 2010, the 2nd World Conference on Research Integrity released the "Singapore Statement on research integrity" (www.singaporestatement.org). It laid out four fundamental principles (honesty, accountability, professional courtesy and fairness and good stewardship of research) and 14 rules of conduct. These are:

- Integrity and trustworthiness of research.

- Adherence to regulations.

- Appropriate methods, critical analysis, objective and full report of findings.

- Clear and accurate records.

- Sharing research findings.

- List of authors include all those and only those who meet authorship criteria.

- Significant contributors are acknowledged.

- Evaluations and peer review are fair, prompt and rigorous.

- Conflicts of interest are disclosed.

- Public comments are limited to the expertise of the researchers and do not represent personal views.

- Suspected research misconduct is reported.

- Institutions, scientific journals, professional organizations and other agencies have procedures to respond to allegations of misconduct and other irresponsible research practices.
- Institutions create and sustain environments that encourage research integrity through education, policies, and standards.

- Researchers and institutions have an ethical obligation to weigh societal benefits against risk.

The Singapore Statement was translated into many languages and is now endorsed by a large number of Universities, research institutions, councils and other organizations.

The Montreal Statement (2013) focused on "Research integrity in cross boundary research collaborations" and the 4th World Conference in Rio (2015), underlined the need for training of scientific integrity for researchers in all fields of scientific endeavor.

The European charter of researchers focused on the recruitment and mobility of researchers in Europe (www. europa.eu.int/eracareers/europeancharter); the European Code of Conduct for Research Integrity explained the principles of research integrity and gave some advice for handling of MR and QRP (www.esf .org/ fileadmin/Public_documents/Publications/Code_ Conduct_ResearchIntegrity).

The NF X50-553 standard was published by the French Standardization body in 2014 [10]. It is part of the ISO 9001 [11] family of standards for sound and efficient organization and conduct of activities and specialized on the "Management of research activities". It provides information on values in science, role and responsibility of directors, management of resources, conduct and steering of research and capitalization and valuation.

Other codes and standards, more methodology-linked or specific for a given field of investigation, exit but are not quoted here.

\section{What has been and what can be done to detect and deal with scientific misconduct and questionable research practice?}

The research community shares a common set of values; these are sometimes formally expressed, but most research institutions and universities do not specifically communicate on their values. Science is a system with its rules and functioning. Now codes of conduct exist for scientific integrity in general and different codes of conduct have also been established for various areas of science. These codes, however, tend to be very general statements. Putting the existing rules into practice, especially by research management, is not always simple. When a science manager (head of a team, a department, an institution), wants to improve research practice, the information and communication of the existing codes and charters is crucial, but often insufficient. Pinning them on a pin-board does not automatically change managerial practice. However, other ways have been found to reduce scientific misconduct through prevention, education and a strong scientific culture. Detection and dealing with SM and QRP involves all stakeholders in science. 
Establishment of definitions for SM and QRP was provided by academic societies and conferences. They provide relatively general definitions and codes. Scientists in the specific fields of research should think of field-specific and methodology-specific guidelines in order to provide more direct and practical guidance; academic societies and associations could be the frame for such a project.

Procedures for reporting and investigating misconduct and questionable practices need to exist at the level of institutions, universities or entities which benefit from sufficient confidence and authority and who can provide a single entry system for reporting and investigating [12].

Scientific journals are also challenged by this problem because SM and QRP issues may arise during the peer reviewing process or once the scientific article has been published and is read by other researchers. Guidelines of the editors for researchers who submit papers and for peerreview should be available. Suspected cases of SM and QRP should be reported by reviewers, recorded and handled by the journal. SM and QRP should be reported by scientific journals.

Publication of scientific findings heavily relies on the process of peer review.

The whole process of peer review of scientific articles has been criticized. Peer review is free of charge and reviewing a larger number of articles can represent too much work and time for reviewers. Some reviewers may ask a third party (co-workers, etc.) for help or do not invest the time necessary for in-depth analysis.

Reviewers have access to confidential data and new ideas. Confidentiality agreements should exist, have to be signed and respected. Possible conflicts of interest have to be revealed and prevented.

The Council of Science Editors has established editing rules that were published in a White paper on Promoting Integrity in Scientific Journal Publications, which is regularly updated (http://www.councilscienceeditors . org/wp-content/uploads/entire_whitepaper).

In most cases, allegations of misconduct are made by coworkers and other members of the institution; reviewers, too, note inconsistencies, redundancies or question the names of authors on a manuscript. Whistle blowers often hesitate to report an allegation because relationships (also dependencies) are strong in science. Students and young researchers do sometimes not dare report what seems to them to be SM or QPR, because they depend on the head of a team or institution for their research and their career. Senior researchers and reviewers may not report items of concern because they realize that they may be in a situation in the future where they depend themselves on the favorable outcome of an evaluation. Only when rules are strict, measurable, transparent and ubiquitous, can objective evaluation take place.

Investigation needs time, effort and specific knowledge. These can be made available by one or the other (university, institution, journals) or on a shared basis. A dedicated and identified person, or group of people (Office of research integrity, etc.) should exist and their existence should be known to all parties involved. Rules, control mechanisms and ways to handle misconduct of any kind need to be established.

Punishment of SM includes loss of funding from a particular agency, dismissal from an academic appointment and, in countries where SM is punished by law, financial punishment or even prison sentence.

Although different stakeholders share responsibilities for flaws in the system, investigators must be accountable to the scientific community as well as to society for the findings they publish and for the conclusions they draw.

\section{What can and what has been done to prevent bad scientific practice?}

\subsection{Data management}

Responsible research conduct refers to the ability to justify scientific conclusions on the bases of data acquired (data mining), the ability to account for the data (organization, protection and storage), its verification by the scientific community (availability of data and tools, reliability, debate) and a commitment to ethical management of the study and the humans involved.

Experimental sciences heavily rely on the reliability of data and measurements. For this reason, proper methodology has to be defined separately by field or by the experts of a given method. The storage, security and availability of data have to be guaranteed. When measurements are performed, the metrology of the equipment plays a crucial role. Records of testing of the equipment and definition of appropriate precision (confidence window) are necessary.

Before publication, reviewers and the scientific journal may claim to see raw data, experimental set up, protocols, observation records and so forth. In many cases, researchers have difficulty to deliver these in a short period of time, because lack of organization and proper storage protocols. Poor quality engineering of documentation accounts for loss of time and trouble in the team when raw data have to be made available. After publication too, raw data or specific information may be claimed by readers, who obtained conflicting data in similar conditions. Indeed, as J Budd turns it, "if studies cannot be repeated, or if data cannot be examined by others, the community has only the word of the researchers that protocols were followed, that appropriate methodologies were applied and that findings can be found to be valid and reliable" [6]. Therefore, several institutions, such as the US National Institutes of Health (NIH), are in the process of launching "Reproducibility programs".

\subsection{Information sharing}

Science is based on the sharing of knowledge; however, in practice, the handling of the requests of colleagues and competitors differs a lot between individuals and between disciplines. Wicherts et al report that from an analyzed number of 141 articles, $73 \%$ of the authors did not share 
their data despite of considerable insistence and effort of the team to claim those data [13]. Wicherts admits that is his field, psychology, most people "fail to document their data in a way that allows others to quickly and easily check their work" [14].

\subsection{Scientific practice}

Some people believe that prevention of bad scientific practice is impossible, because, first, it is part of human nature and second, it is very difficult to detect unless you spend a comparatively large time on detection. However, other scientists believe that the issue is important because it can erode trust and support of the scientific community by citizens, potentially compromising public funding. Furthermore, there are preventive actions that can be taken to address the issue.

Efficient prevention must take place at the institutional, community and individual level. It requires the engagement of those responsible, appropriate tools and the time necessary to convince researchers of its importance. Since the type of research differs widely between different fields, specific actions have been taken by different communities. More advanced fields of research can help by proposing standards and tools.

Scientific institutions, societies, journals and the scientific community in a given field carry a certain amount of responsibility. They are partly or wholly responsible for evaluation practices and should reflect on possible overvaluation of scientific publications and publication in high profile journals. Incentives for more publications, including promotion, tenure and even cash rewards should be handled with great care. Negative data, validation of a particular methodology or scientific approach should also be valued by the scientific community and research organizations.

These organizations must make sure that rules are in place, that they are well documented and known to all. They should have guidelines to handle scientific misconduct. Institutions sometimes seem to deliberately ignore questionable behavior, in order to protect their own reputation. However, progress has been made with the legal protection of whistle-blowers and ombudsmen (http:// ombudsman.nih.gov) are in place in many universities. In addition, offices of scientific integrity now exist in most institutions.

Scientific journals and editors have long put pressure on authors to provide "perfect" e.g. evident and straightforward data and illustrations; also, methods were to be described succinctly in order to leave space for interesting findings, often leaving out critical information that is necessary for proper interpretation and reproducibility. Recently, Nature Publishing Group announced several editorial measures aimed at improving the consistency and quality of reporting life sciences, including abolition of restrictions in length of methods sections, providing authors with a checklist to reveal methodological parameters, and requiring both a thorough description of statistics and increased transparency of image processing [15].
The "scientific network" is an important contributor to the organization of science. In addition to their everyday work on their particular research project, researchers also serve on boards of scientific associations, committees or journals. In that capacity they see and evaluate the work done by other researchers in their field and evaluate research projects, doctorate candidates and careers of researchers. By doing so, they are in a position to evaluate the intrinsic quality of the research, the methodology used and the reasonableness of the data interpretation. Thus, reviewers can have influence on the "gold standard" of their discipline. Scientists themselves know the weak points of their field and can engage in debates about methods, data and conclusions with their peers. The peer related process is an important feature of research and should be used to contribute to the setting of usable rules. It can contribute to the awareness (where it is lacking) that proper conduct of research is the basis of trustworthiness that sound research is necessary for collective progress and that only ethical research management will be sustainable in the long run.

How can we learn about best practices, scientific integrity and ethical and efficient research management, and make progress in our practice? Participation in consensus groups, standardization committees and work groups at the level of scientific societies not only ensures that everybody has up to date information, but also allows individual researchers and groups to play a significant part in performing responsible and accountable research.

At the level of prevention, it is their duty to think about the impact of evaluation of research in this process. In the evaluation of individuals and research projects, an overestimation of the number of published articles and the high profile of the journal should be avoided. The quality of study design, data collection and treatment as well as difficulties, in the management of the study (number of individuals and teams involved, training of students, setting of standards and breakthroughs) should also be taken into account.

Scientific studies are very diverse in their size and organization. When data are collected and interpreted by a single researcher or a small number of individual scientists, the risk for SM and QRP is higher than when a large team works together and discusses study design, data collection and so forth. It is therefore important that research groups and scientific societies serve as a "forum" for debate and exchange.

Agreement on authorship is a prerequisite for responsible publication practice. Some journals require that each author gives detailed information on his/her contribution, explicitly approves the article and takes full responsibility for contribution and the article us such. Precise rules for authorship and ranking of authors exist and avoid guest authorship or ghost authorship (http://www.councilscienceeditors.org/ wp-content/uploads/entire_whitepaper). A similar engagement could be taken by the reviewers in peer review. They should sign a guarantee that they have thoroughly reviewed the manuscript, data, literature 
(omissions, plagiarism) and conclusions (speculations). Conflicting interests between the authors and the reviewer should also be revealed.

\subsection{Teaching}

The scientific attitude and an ethical mind-set are most easily passed on in a "one to one" relationship between a senior and a junior researcher. They should be supported by formal teaching programs in study design, statistics, scientific integrity, ethics and research management. The Leuven University, (www.kuleuven.be/research/ integrity/procedures) for example, has designed an online training program.

An ethical mind-set also has to be "internalized" individually by each researcher and kept alive during his/her career through input from the scientific community, debate, and collective problem-solving when problems in good research practice occur. Universities are starting to establish courses in SM, QRP and EERM designed for researchers at different levels (pre or post doctorate or for life-long-learning). The scientific community in each field should make sure that everyone is aware of the need and of the existence of these programs. In their 2013 report [3], the Royal Netherlands Academy of Arts and Sciences emphasized that "all researchers must deliberately cultivate and demonstrate a scientific mind-set (p. 43)" and that "informal social control can also have a positive effect" (p. 44). Moreover, they suggested that researchers take a professional oath and solemnly affirm that they will comply with the Netherlands Code of Conduct for Scientific Practice (p. 62).

\subsection{Management tools}

Quality engineering is based on continuous improvement, setting objectives and their attainment and identifying defaults.

At the level of the research team, prevention begins with a strong conviction of the head of the team. It has to be made clear what values and standards you share and that quality checks are part of good science. Protocols are to be respected and modifications are introduced (and documented) only for a new set of data collection and not because of a sudden change of mind. Co-workers, students and voluntary aids are respected and the relationships are transparent with respect to responsibility, conduct and valuation of the work. Ethical and efficient research management has to be promoted and known by the team.

In a quality management system (according to the international standard ISO 9001: 2015), shared values are translated by the responsible researcher (principle investigator, team leader, head of department) into down-toearth objectives. Specific actions are designed and performed to attain the objectives and their efficiency is monitored by the measurement of pre-defined indicators.
The quality management policy of the research group or department will adhere to these values and identify the person (quality manager) who will steer the quality approach.

Documentation is commonly considered as being tedious and time-consuming and often felt by researchers as an administrative burden in conducting academic research. However, records of findings and the conditions of their discovery are essential. Documentation not only concerns discoveries, but also planning of a study, permissions requested and obtained, check-lists and procedures used to deal with important management issues. Guidance for good documentation in general can be found in the ISO 9001: 2015 standard; for scientific documentation in standard NF X 50-553.

Documentation that is used for scientific publication has to be properly organized in order that individual data can be rapidly found. In a "publi-book", individual data, the context of the finding, protocols and tools used etc. are summarized and the site of storage (paper, objects, samples and computer files) is clearly indicated. The publibook is a document that is written by the corresponding author at the same time as the publication. He/she makes sure that for each published data point in a table or a figure, the raw data are available, fully documented and the site of storage is well identified. In this way, every time, a data point in a figure or table is questioned or needs to be reexamined, the treatment of the data down to the raw measurements and all calculations are readily available. The system should be regularly tested (audited) in order to assure efficiency of retrieval.

\subsection{The management tool box of EERM}

Problems and challenges in SM, QRP and bad research management can be tackled by a number of management tools which we have adapted from data management, project management, quality management and quality assurance, risk management and other management tools, which we call the "EERM tool box".

When problems need the attention of the science manager, (head of team or office, head of department, of institute, etc.) he/she will first identify the possible thread or consequence of the observation. Management of the possible consequence can include, when necessary, a formal assessment, evaluation of the probability and the degree of the thread and different questioning methods. When the number of identified threats is too large, a ranking order has to be established. In Table 1, we give a selected list of threads that are posed by scientific misconduct, bad scientific practice and unethical and inefficient research management. These consequences and threats need to be dealt with and can sometimes be difficult managerial challenges. In Table 2, we offer an overview of tools which are useful when a particular managerial challenge occurs and must be treated in an ethical and efficient way. It can be used as a tool box, containing different management tools which are fit for treating one or several challenges 
Table 1. Problems encountered and their consequences or threats for good scientific practice.

\begin{tabular}{|c|c|}
\hline Problem encountered & Consequence/threat \\
\hline Scientific misconduct. & Loss of trust. \\
\hline Fabrication. & Lacking identification, absence of proof. \\
\hline Falsification. & Absence of control of data, absence of proof. \\
\hline Plagiarism. & Lack of identification. \\
\hline Questionable research practice. & $\begin{array}{l}\text { Inappropriate or poor methodology, incorrect } \\
\text { data, wrong conclusions. Doing wrong to } \\
\text { science and society. }\end{array}$ \\
\hline $\begin{array}{c}\text { Guest (gift, ghost) authorship } \\
\text { Deleting from the list of authors a person } \\
\text { who contributed significantly to the article } \\
\text { Not giving credit or recognition to persons } \\
\text { who gave help, support in part of the } \\
\text { research or technical assistance, without } \\
\text { qualifying for the author-status. }\end{array}$ & $\begin{array}{l}\text { De-motivation of co-workers, loss of } \\
\text { potential collaborations. Loss of trust of } \\
\text { the scientific community. }\end{array}$ \\
\hline $\begin{array}{l}\text { "Salami-slicing" of a publication (cutting } \\
\text { down coherent data and findings into } \\
\text { several publications). }\end{array}$ & Loss of reputation. \\
\hline $\begin{array}{c}\text { "Cherry picking" (reporting only data } \\
\text { which sustain the hypothesis or lead to } \\
\text { positive results) or "massaging" data } \\
\text { (deleting undesired data points or observations). }\end{array}$ & $\begin{array}{l}\text { Incorrect data, wrong conclusions } \\
\text { Doing wrong to science and society. }\end{array}$ \\
\hline $\begin{array}{l}\text { Photo manipulation for "improving" images and } \\
\text { photo records by using computer software } \\
\text { without giving precise information on the software } \\
\text { used and what was modified on the image. }\end{array}$ & $\begin{array}{l}\text { Incorrect data, wrong conclusions } \\
\text { Doing wrong to science and society. }\end{array}$ \\
\hline Inadequate record keeping. & $\begin{array}{c}\text { No possibility to prove claims. } \\
\text { No possibility in finding previous } \\
\text { data that can then be compared to new data. }\end{array}$ \\
\hline Failure to disclose conflicts of interest. & Lack of objectiveness. Doing wrong to science and society. \\
\hline $\begin{array}{l}\text { Failure to share information, methods, } \\
\text { tools, etc. with the scientific community. }\end{array}$ & Jeopardizing the "scientific method". \\
\hline Non-ethical and inefficient research management. & Loss of trust. Loss of resources \\
\hline Disrespect shared values. & Loss of trust. Demotivation of co-workers \\
\hline Lack of respect of co-workers and collaborators. & $\begin{array}{l}\text { Demotivation of coworkers, no incentive } \\
\text { to be creative, or give their best. Bad climate at the } \\
\text { work-place and low quality of life. }\end{array}$ \\
\hline Improper training, teaching and advice of students. & Jeopardizing the "scientific method". Loss of reputation \\
\hline Repeat confidential data or information. & Failure to protect confidential information \\
\hline $\begin{array}{l}\text { Insufficient project management and } \\
\text { management of collaborative studies. }\end{array}$ & $\begin{array}{c}\text { Failure or delay in project or collaboration. } \\
\text { Loss of reputation. }\end{array}$ \\
\hline Health, safety and quality of life issues of a team. & Legal issues. Loss of reputation. \\
\hline Non-adherence to rules and regulations. & $\begin{array}{l}\text { Scientific risk, management risk, } \\
\text { financial risk, legal risk, etc. }\end{array}$ \\
\hline $\begin{array}{l}\text { Lack of management of interactions in projects } \\
\text { which involve different teams and systems. }\end{array}$ & $\begin{array}{l}\text { Loss of efficiency and communication } \\
\text { in connected processes. }\end{array}$ \\
\hline
\end{tabular}

or threads and was designed to match easily threads and tools.

When providing information or proof, quite naturally, record keeping is necessary. Audits, conducted by the authors on a regular basis, show that in $50 \%$ of all cases, retrieval of scientific data, recorded by the filing system, appears to be tedious, so that finding data takes a lot more time than expected. Intellectual property has to be ade- quately identified and securely stored because it represents the scientific patrimony of a research institution and may be valorized scientifically or economically. Here too, proof is important (confidentiality statement, meeting record).

Good practice in data mining can and has to be taught. However, whether "decent citizenship" can be taught, is questionable. As DL Weed [5] pointed out, increasing the ratio of senior to junior scientists (provided resources 
Table 2. Managerial challenges and available tools.

\begin{tabular}{|c|c|}
\hline Consequence/threat & Management tool \\
\hline Lacking identification, absence of proof & $\begin{array}{l}\text { Policy of EERM, written procedures and } \\
\text { record keeping, continuous improvement. }\end{array}$ \\
\hline $\begin{array}{c}\text { Absence of control of data, absence of proof } \\
\text { for existing findings }\end{array}$ & Record keeping and archiving of findings. \\
\hline $\begin{array}{c}\text { Lack of control of data, lack of proof } \\
\text { of proper collection, treatment and reporting }\end{array}$ & $\begin{array}{l}\text { Record keeping of procedures, findings, } \\
\text { additional information, logbook or lab } \\
\text { journals during the study, "Publi-book" when } \\
\text { preparing a scientific article. Site visits } \\
\text { of principle investigator. }\end{array}$ \\
\hline $\begin{array}{l}\text { Identification, lack of proof of ideas } \\
\text { and writing of text }\end{array}$ & $\begin{array}{l}\text { Appropriate software for detection, confidentiality } \\
\text { statement, quotation of references }\end{array}$ \\
\hline $\begin{array}{l}\text { Inappropriate or poor methodology, incorrect } \\
\text { data, wrong conclusions do harm to science } \\
\text { and society when published }\end{array}$ & $\begin{array}{l}\text { Teach and live good research practice. } \\
\text { Procedures must be precise, fully documented } \\
\text { and validated. Methodology needs to be state } \\
\text { of the art or indicated as being "experimental". } \\
\text { When measuring equipment is used it should } \\
\text { be properly calibrated and recorded. } \\
\text { Guidelines, of what is good research } \\
\text { practice have been elaborated in a given } \\
\text { field of research and must be respected. }\end{array}$ \\
\hline $\begin{array}{l}\text { Non-recognition of contribution, demotivation } \\
\text { of co-workers, loss of collaborative possibilities. } \\
\text { Loss of trust by the scientific community }\end{array}$ & $\begin{array}{l}\text { Use of well-defined authorship rules and } \\
\text { regular assessment. Decision making based } \\
\text { on facts. }\end{array}$ \\
\hline Loss of reputation in the scientific field & Respect publication roles of journal. \\
\hline $\begin{array}{l}\text { Incorrect data, wrong conclusions. } \\
\text { Doing harm to science and society }\end{array}$ & $\begin{array}{l}\text { Best practice in study design and planning. } \\
\text { Identification of critical steps of the study, risk } \\
\text { assessment and handling. Record keeping } \\
\text { of findings, sound statistical analysis. } \\
\text { Training and control of raw data. }\end{array}$ \\
\hline $\begin{array}{l}\text { Modified images, wrong conclusions. } \\
\text { Doing harm to science and society }\end{array}$ & $\begin{array}{c}\text { Best practice in image analysis } \\
\text { and reproduction. }\end{array}$ \\
\hline $\begin{array}{c}\text { No possibility to prove claims. No possibility } \\
\text { to find previous data and compare them } \\
\text { properly to new data }\end{array}$ & $\begin{array}{l}\text { Correct and complete record keeping. } \\
\text { Safeguarding records, Construct arborescence } \\
\text { in data management (e.g. track record } \\
\text { from raw data to published data). }\end{array}$ \\
\hline $\begin{array}{c}\text { Lack of objectiveness. } \\
\text { Doing harm to science and society }\end{array}$ & $\begin{array}{l}\text { Decision making and any kind of evaluation } \\
\text { are based on objectiveness. This requires a } \\
\text { standard which has to be respected. If } \\
\text { objectiveness can be questioned because } \\
\text { of personal or institutional interests, this has } \\
\text { to be disclosed. }\end{array}$ \\
\hline Jeopardizing the "scientific method" & $\begin{array}{l}\text { The "scientific method is based on an } \\
\text { unwritten code of shared values: openness } \\
\text { and sharing of information is part of this. } \\
\text { When not respected, a delay in scientific } \\
\text { progress and common awareness will result. } \\
\text { Teaching is part of the sharing of information. } \\
\text { Teaching needs to be done conscientiously } \\
\text { and be of highest quality. }\end{array}$ \\
\hline $\begin{array}{l}\text { Loss of trust, loss of resources. } \\
\text { Doing harm to science and society }\end{array}$ & $\begin{array}{l}\text { All three occur when research management is } \\
\text { lacking ethos and efficiency. The reasons for } \\
\text { this lack must be analyzed. Defaults recorded } \\
\text { and analyzed. Objectives can be fixed to set } \\
\text { endpoints for actions. They have to be } \\
\text { monitored to assess efficiency. }\end{array}$ \\
\hline Loss of trust. Demotivation of co & $\begin{array}{l}\text { Shared values are used as guidance in every } \\
\text { day practice. If they are not respected, they } \\
\text { are not only useless but counter-productive. }\end{array}$ \\
\hline
\end{tabular}


Table 2. Continued.

\begin{tabular}{|c|c|}
\hline $\begin{array}{c}\text { Demotivation of coworkers. } \\
\text { No incentive to be creative, give their best. } \\
\text { Bad climate at the work-place, low quality } \\
\text { of life. }\end{array}$ & $\begin{array}{l}\text { Motivation, quality of life and a feeling of } \\
\text { belonging are important factors for } \\
\text { motivation. In quality management, } \\
\text { coworkers and collaborators are considered } \\
\text { interested parties and one of the requirements } \\
\text { of good management is to identify the } \\
\text { specific needs of each individual and monitor } \\
\text { their degree of satisfaction. Treating coworkers } \\
\text { and collaborators as interested parties is } \\
\text { designed to stabilize and solidify the } \\
\text { organizational structure. It builds trust } \\
\text { and motivates everybody to fully } \\
\text { collaborate and give their best. } \\
\text { Recognition of individual contributions. }\end{array}$ \\
\hline $\begin{array}{c}\text { Lack of protection of confidential } \\
\text { information. }\end{array}$ & $\begin{array}{c}\text { Confidentiality statement and compliance } \\
\text { with it. }\end{array}$ \\
\hline $\begin{array}{l}\text { Failure or delay in project or collaboration. } \\
\text { Loss of reputation. }\end{array}$ & $\begin{array}{c}\text { Project management in research and } \\
\text { management of collaborations represent a } \\
\text { specific challenge. Standard NF X 50-553 } \\
\text { provides information. }\end{array}$ \\
\hline Legal issues and/or loss of reputation. & $\begin{array}{l}\text { Not complying with legal requirements will } \\
\text { raise liability issues; therefore the help of } \\
\text { professionals should be sought. Respect of } \\
\text { the quality of life of a team improves } \\
\text { reputation. and stabilize a research group. }\end{array}$ \\
\hline $\begin{array}{l}\text { Scientific risk, management risk, } \\
\text { financial risk, legal risk, etc. }\end{array}$ & Standard BS 10500 provides information. \\
\hline $\begin{array}{l}\text { Loss of efficiency and communication } \\
\text { in connected processes. }\end{array}$ & $\begin{array}{l}\text { Many research projects and teams rely in } \\
\text { their daily work on support structures, other } \\
\text { teams, or they might be part of a larger } \\
\text { research structure. The different activities } \\
\text { must be well coordinated, for more efficiency } \\
\text { and less defaults in the overall process. } \\
\text { Individual activities should be considered } \\
\text { as individual processes and a process-oriented } \\
\text { management structure such as in } \\
\text { ISO } 9001 \text { helps to prevent poor coordination. }\end{array}$ \\
\hline
\end{tabular}

and excellent researchers and teachers are available) can provide primary prevention of scientific misconduct and possibly also secondary prevention (e.g. when SM has already been detected. Transparency of practices (authorship, rank of authors, recognition of contribution of individuals to scientific results and discoveries, etc.) is the tool that helps to maintain trust and motivation of a team.

Transparency also applies to methods and scientific tools. Although research is highly competitive, the "scientific system" relies on openness, sharing of information and scientific tools. At least in a team, collaboration should stand over competition - transparency and fairness in management are probably the best tools to favor collaboration. Specific quality-objectives can be fixed by the head of a team and actions should be undertaken (write down the rules, audit the system regularly in order to check if rules are respected) to promote EERM.

\section{Conclusion}

For a long time, it was assumed that the scholarly records will self-correct with time, through debate among scientists with conflicting views and through opposing publications, so that "the truth" will gradually emerge. Today, pressure on researchers is high (publish or perish), the number of publications per annum has sky-rocked and the cumulative weight of evidence for a given finding requires an increased time span. The number of follow-up publications that are based on the preceding finding will also increase and provide "noise" in the mass of information. If a finding was wrong because of fraud or "sloppy science", the consequences are potentially immense in terms of lost time and need for rectification, dys-information, trust in science and economic impact. There is overall consensus that the scientific community and all its members should 
treat misconduct and bad research practice seriously. Additional or stronger laws and rules are not necessarily required; codes of conduct and of ethics also exist today. The mere fact to know that a code of conduct exists does however not automatically change the practice of a researcher. The problem lies rather in the awareness of the scientific community and in the availability of tools for prevention. Whether prevention works for SM is under debate $[5,16]$, but easy to handle tools should help research managers improve the quality of their management and implement good practice.

Information and cultural acceptance of ethical research management has to be wider spread.

Ethical and efficient research management has to be taught to doctoral students with regular updates for all scientists.

Scientific integrity has to be handled at the institutional level with appropriate procedures and practice. Whistle-blowers, but also individuals under investigation for wrong doing must be protected by the institution. Fraudsters have to be treated with severity but fairness [17].

Preventive measures should be taken at all levels and by all means possible. Management systems such as project management and quality management have been adopted by research organizations and provide valuable tools for preventive actions by assuring transparency, traceability, factual decision making and so forth.

Prevention and handling of unethical research management involves all stakeholders in research. The Inserm quality network (RIQ-Réseau Inserm Qualité) tries to do its part by developing and promoting quality management in research and EERM. The here proposed tools will be field-tested in different laboratories to check their efficiency and for further improvement.

Methods for inter-laboratory comparisons exist, and reproducibility studies will be initiated [18]. Data, protocols and methodology need to be validated, preferably collectively. Comprehensive description of the context in which observations were made and documentation of the data generated and transparency and the willingness to share tools and information are essential.

Scientific journals and reviewers have an important role to play in the enforcement of existing rules. Scientific institutions, associations and societies should play their part and initiate, sustain and make tools and help available to all who do not consider that the self-regulatory action of the system is enough.

Aside from measures taken by different parties (scientific journals, funding bodies and institutions) researchers themselves apply of a toolbox for research management as is outlined here. Unfortunately, things do not fall into place just by themselves. Institutions and heads of teams have to express their willingness to insure high quality research and assist in the use of appropriate tools. They should elaborate and defend a statement or policy of quality of research and ethical research management. The team then needs to translate these "values" into concrete and attainable objectives. The members of team need to de- sign actions to attain the objectives and measure their efficiency. Trouble-shooting is also part of this process of continual improvement. Special attention should be paid to young researches and newcomers to the team in order to improve knowledge and competence management (in particular, during the starting phase) and transfer of information back to the team in the ending phase of their contribution to a project. The quality of life of the members of a team and efficient and ethical management of collaborations are as important in research as in corporate management.

Research relies on top-notch methodology, technical skills and competence. In addition, it involves and impacts human beings and therefore must also deal with things like creativity, critical thinking, developing a win-win relationships with others, competition and ethical behavior.

Awareness of the latter is a new challenge, which requires as a response to not only improve the technology for research but also research management.

\section{References}

1. Piltdown man, www.nhm.ac.uk/our-science/ departments-and-staff/library-and-archives/ collections/piltdown-man.html

2. A.R. Jensen, Scientific Fraud or False Accusations? The Case of Cyril Burt, in Research Fraud in the Behavioral and Biomedical Sciences, edited by D.J. Miller, M. Hersen (John Wiley, New York, 1992)

3. Royal Netherlands Academy of Arts and Sciences, Responsible research data management and the prevention of scientific misconduct. Advisory report by the committee on scientific research data, 2013

4. N.H. Steneck, Introduction to the Responsible Conduct of Research, Office of Research Intégrity (ORI), 2007

5. D.L. Weed, Preventing scientific misconduct, Am. J. Public Health 881, 125-129 (1998)

6. J.M. Budd, The Stapel case: an object lesson in research integrity and its lapses. Synesis: J. Sci. Technol. Ethics Policy G47-G53 (2013)

7. M.L. Grieneisen, M. Zhang, A comprehensive Survey on retracted articles from the scholarly literature, PLoS One 7, e44118 (2012)

8. R. Van Noorden, The trouble with retractions, Nature 478, 26-28 (2011)

9. V. Katavic, Retractions of scientific publications: responsibility and accountability, Biochemia Medica 24, 217-222 (2014)

10. Management des activités de recherché, NF X 50-553 (ICS: 03.100.10; 03.120.10), 2014

11. Quality management systems-Requirements, NF EN ISO 9001 (ICS: 03.120.10), 2008

12. P.J. Snyder, L.C. Mayes, W.E. Smith, The management of scientific integrity within academic medical centers (Academic Press, 2015), p. 13

13. J.M. Wicherts, D. Borsboom, J. Kats, D. Molenaar, The poor availability of psychological research data for reanalysis, Am. Psychologist 61, 726-728 (2006)

14. J.M. Wicherts, Psychology must learn a lesson from fraud case, Nature 480, 7 (2011)

15. Editorial, Announcement: Reducing our irreproducibility, Nature 496, 398 (2013) 
16. H. Coates, Ensuring research integrity, The role of data management in current crises, College Res. Libraries News 75, 598-601 (2014)

17. R. Gallagher, Fairness for fraudsters, The Scientist 7, 1333 (2007)

18. F.S. Collins, L.A. Tabak, Policy: NIH plans to enhance reproducibility, Nature 505, 612-613 (2014)

\section{** List of authors (alphabetical order)}

Adier Christophe, Inserm U 1070, Poitiers, France Alvarez Marion, Inserm Cermep, Lyon, France Audigane Leslie, Inserm UMR1087, Nantes, France Bareille Reine, Inserm U 1026, Bordeaux, France Baudouin Massot Béatrice Inserm UMRS 702, Paris, France

Brand Céline, Inserm UMR 837, Lille, France

Brunel Meunier Nadège, Inserm UMS 30, UPMC, Paris,

France

Calard Isabelle, Inserm UMR 1089, Nantes, France
Carreno Marie-Paule, Université, Paris 7, France Corvo-Chamaillard Staëlle UMR 837, Lille, France Chevalier Catherine US 16, Nantes, France

Fohrer Ting Hélène, Inst.des Cordeliers, UPMC, Paris, France

Fournier Sandra Inserm Desp, Paris, France Joseph-Mathieu Patricia, Inserm Transfert, Paris, France Lebret Nelly, IMRB, Créteil, France Lefebvre Caroline ANR, Paris, France Letondal Patricia, UMR 1098, Besançon, France Lottin Yousra Université Paris 7, France Maccota Céline Inserm DR, Nantes, France Moreau Elisabeth Inserm US 019, Villejuif, France Mura Anne Marie, Inserm Ciphe, Marseille, France Rémy-Jouet Isabelle, UMR 1096, Rouen, France Philippe Aurélie, Inserm DR Marseille, France Rémy Séverine, Inserm U 1064, Nantes, France Rostagno Philippe, Inserm U 1065, Nice, France Schiltz Corinne, Inserm DRH, Paris, France Tinland Marie-France, Inserm U 901, Marseille and Eva Giesen, Inserm, DG, Paris, France 